\title{
Peculiarities of the Occupational Crisis of Heads of Educational Organizations
}

\author{
Olena Bondarchuk ${ }^{1, *}$, Valentyna Balakhtar ${ }^{2}$, Alla Moskaljova ${ }^{1}$, Maksim Moskalov $^{1}$ \\ and Kateryna Balakhtar ${ }^{3}$
}

\begin{abstract}
${ }^{1}$ Department of Management Psychology, State Institution Higher Education "University of Educational Management”, Kyiv 04053, Ukraine

${ }^{2}$ Department of Pedagogy and Social Work, Yuriy Fedkovych Chernivtsi National University, Chernivtsi 58012, Ukraine ${ }^{3}$ Department of Communicative Linguistics and Translation, Yuriy Fedkovych Chernivtsi National University, Chernivtsi 58012, Ukraine

*Corresponding author. Email: bei.07@ukr.net
\end{abstract}

\begin{abstract}
The study dwells on the analysis of the occupational crisis peculiarities of the heads of educational organizations, which is seen as an experience of professional problems and arises as a result of blocking the ability to achieve professional goals having personal meaning for leaders. This comprehensive methodological study combines surveys and a quantitative approach. The study has derived from was conducted among the students of the State Institution of the Higher Education "University of Education Management" (Central Institute of Postgraduate Education, Kyiv). The total sample size was more than 2000 (2060) heads of educational organizations from different regions of Ukraine, who have undergone advanced training in this institution for the past 5 years. Based on the analysis of the peculiarities of the occupational crisis of the heads of educational organizations, we applied our model of the occupational crisis, consisting of cognitive and reflexive, affective and conative and regulatory components. We proved the validity and the possibility of using the model of the occupational crisis of heads of educational organizations and a set of psychodiagnostic techniques to monitor the peculiarities of the occupational crises manifestations.

The monitoring of the occupational crisis is much valuable using computer tools since quickly accessing lots of people, obtaining information, performing qualitative and quantitative data analysis. We found the inability of some surveyed managers to constructively overcoming the occupational crises. The obtained results testify to the expediency of developing a program of special psychological interventions that will be of identifying the specific ways to constructively emerge the heads of educational organizations from the occupational crisis, taking into account the individual characteristics of its manifestation.
\end{abstract}

Keywords: an occupational crisis, the head of educational organization, model of the occupational crisis,

monitoring, model of components

\section{INTRODUCTION}

Nowadays, human interaction with the environment often acquires a pre-crisis or crisis nature in recent times caused by a great number of challenges. The last of which is COVID-19, which led to an increase in the number of crisis phenomena in all spheres of public life, including the professional activities of leaders of educational organizations. This causes not only leaders of educational organizations to be aggressive, irritable, depressed, emotional, and cynical, with physical and mental fatigue but also all employees of the educational process and their families [1, p.313]. It leads to reduced interest in work, reassessment of professional opportunities and values, change of ways of activity performance and relationships with others, etc. The professional activity of educators is amongst the most important pursuit for society, and dissatisfaction of the educator with his/her professional position; unrealized opportunities affect the quality of teaching, socio-psychological climate and well-being of the team, personal growth of students. The head of any organization must create the right conditions so that staff (employees) may work successfully to overcome crises. This is especially true of educational organizations aimed at educating future generations, and, in particular, through the retransmission by leaders and teachers of appropriate behaviours. But practice and research show that leaders are often not ready, because they are in a crisis or pre-crisis state, experiencing problems at the physiological (headaches, diseases of the respiratory, cardiac and other systems), psychological levels (mental disorders depression, frustration, anxiety etc.), behavioural changes (tobacco addiction, alcoholism, violence[2;3;4;5;6]. 
However, a significant number of them do not have adequate means of overcoming such conditions. Overcoming professional difficulties by the heads of education organizations is a remarkably difficult task and depends on the influence of many factors and conditions, as well as creates certain contradictions between them. In particular, it requires heads of educational organizations to change their thinking and behaviour; mobilize the organization in times of crisis; set clear priorities and empower people to find and implement solutions that meet these priorities; understand the situation and the way how to deal with it through healthy discussions; to express confidence that the organization will find a way through a difficult situation, but also to recognize the uncertainty of the crisis and the need to find new information.

Instead, the analysis of management practice in education and theoretical analysis of the literature $[7 ; 8 ; 9 ; 10 \mathrm{etc}$. allows making the assumptions about the insufficient ability of a considerable part of heads of education to the constructive decision of professional problems of crisis character. The crisis intervention and prevention have become central to mental health professionals working at schools [11].

That is why the study of the problem of the occupational crisis and it's overcoming by the heads of educational organizations becomes especially relevant since several contradictions between:

- the demand to form the personal potential for the constructive overcoming of crisis by the heads of educational organizations and insufficient theoretical justification of this process in psychological science;

- the desire of the heads of the organizational organizations to avoid the negative consequences of the occupational crisis and the lack of personal readiness;

- the expediency of organizing the special psychological training for the heads of education in constructive ways to overcome the occupational crisis and the lack of appropriate psychological technologies.

The resolving of these contradictions involves studying the issue of modelling and monitoring the overcoming of the occupational crisis of heads of educational organizations.

\section{LITERATURE REVIEW}

In the period of global socio-economic changes, the problem of crisis is not only personal but also professional, caused by relation changes between adults, and has become relevant. At the same time, as experts from various spheres of public life point out $[12 ; 13 ; 14]$, the psychological aspect of this problem has become important in recent years.

Theoretical analysis of the scientific literature has made it possible to identify various definitions of the term "occupational crisis" depending on which category the characteristics of such a condition concerned. The concept of "crisis" is interpreted such as a problem that is faced by the individual and which he or she is unable to avoid and solve in a short time in the usual way [15; 16]; tough problem-solving situation that is accompanied by a state of tension in the body and is a reaction to stress [17]; the lack of sufficient resources to cope with work requirements: "A situation in which one loses an idea- the incentive that motivates the person" [18]; situations where homeostatic limits are exceeded by constant destructive factors that lead to both problem-solving or adaptive behaviour and lead to the adaptation and chronic stress reactions $[19 ; 20 ; 21]$. Regarding the occupational crisis, it is comprehended as: a phenomenon in a professional activity that leads to destruction, deformation of the personality structure [22]; a sharp decline in self-esteem, loss of prospects for professional growth, inability to self-realization in the profession [23]; a function of work overload, interpersonal problems and frustration at work, organizational changes, a threat of job loss, and/or family worries [24];

Particularly relevant in the context of our work is the study of achievement needs, the satisfaction of which depends on professional well-being [9]; experiencing professional problems, perceived as professional obstacles that arise as a result of blocking the ability to achieve professional goals that have a vital, personal meaning for the head [25, p.245252]; psychological overcoming, based on a person's awareness of the availability of means of assistance in a difficult situation and the ability to operate as many as possible, which guide to strengthen the sense of control and, consequently, more effectively overcome the problems facing the subject in difficult circumstances [26] the specifics of providing psychological assistance to personal development during the performance of professional activities in educational institutions [7].

The analysis and generalization of the literature sources on the study of this phenomenon give grounds to consider the occupational crisis in the context of the inability of heads of educational institutions to perform their functional duties in the usual way. The occupational crisis identity is characterized by the generation of self-diffidence, inner conflict, awareness of the necessity of self-revaluation, the vagueness of life goals, the lack of understanding of how to live on, the loss of feeling of novelty, being behind the times, etc. [11].

Of considerable scientific interest is the study of features and development of a model of the constructive solution of the professional crisis of leaders of educational organizations, which is seen as experiencing professional problems that arise from blocking the ability to achieve professional goals that have meaningful, personal meaning for leaders.

\section{PROBLEMS AND METHODOLOGY}

Crises accompany the professional activity of each person, including heads of educational organizations (career growth, empowerment, increasing skills, changing status by the standards of the professional field, gaining popularity, material rewards, etc.). Crises affect the wellbeing of leaders, their functioning and health in today's crisis, under the conditions of Covid-19, complex emergencies in areas of military conflict [13] 
To reduce the effect of the negative consequences of crises states on the individuality of the head of the educational organization, the research design for the study was a cross-sectional descriptive survey and quantitative approach (testing). Author's research model consists of three components that demonstrate the features of the manifestation of the occupational crisis of heads of the educational organizations. They are studied on three components: cognitive and reflective, affective, conative and regulatory.

The cognitive and reflective component is determined by the criterion of "cognitive dissonance and negativism" and the following indicators: the predominant focus on the negative aspects of professional life, awareness of the lack of perspective, loss of meaning in life; perception of oneself as a person who is alienated from other people, perception of the professional environment as one that threatens self-realization.

The criterion of the affective component is "affect and stress" and the indicators are the predominance of negative mental states (anxiety, aggression, rigidity, and frustration); disturbance of emotional response, depressed mood; the presence of stress, experiencing a situation as incompatible with ordinary life; functional problems of sleep disorders, deteriorating health.

The conative and regulatory component is determined by the criterion of "aggression and conflict" and the following indicators: the growth of manifestations of aggression and hostility in behaviour, conflict in interpersonal relationships; choice of unconstructive ways of behaving in stressful situations, low efficiency of professional duties.

A set of psychodiagnostic methods is proposed, which is able to be used as a basis for monitoring occupational crises of heads of educational organizations and its components:

1) cognitive and reflective component:

a) to study degree of the predominant focus on the negative aspects of professional life, awareness of lack of perspective, loss of meaning in life and perception of oneself as alienated from other people, perception of professional environment as a threat to self-realization "Questionnaire to identify crises factors and factors overcoming occupational crises by heads of educational organizations"[10]: Scale "Lack of perspective"; Scale "Negative influence of external circumstances"; Scale "Loss of meaning in life"; Scale "State of alienation"; [10] b) Scale "My work environment" of the questionnaire "What is your creative potential?" [27];

c) to identify a low level of self-identification with a successful leader, awareness of the inability to innovatively solve problems in management - methods "What kind of leader are you?", "Ability to solve management problems" (N. Petrova) [27];

d) to determine the level of understanding of the importance of self-regulation as a motive for professional activity - the method "Motives for professional activity" (O. Bondarchuk, L. Karamushka) [7];

2) affective component: a) the method of "Self-assessment of mental states" (G. Eisenk to study the prevalence of negative mental states) (anxiety, aggression, rigidity, frustration) [7]; b) disturbance of emotional response, depressed mood items 4, 5 of the method "Personal profile of crisis" (A. Taras) [7];

c) the presence of stress, experiencing a situation as incompatible with ordinary life - methods "Stress" (according to R. Daft) [27], "Deployment of occupational crises in the heads of educational organisations" (author's development) [7]

d) functional problems of sleep disorders, deterioration of health - items 1, 2 of the questionnaire "Personal profile of the crisis" [7];

3) conative and regulatory component:

a) the growth of manifestations of aggression and hostility in behaviour, conflict in interpersonal relationships methods of "Behavioural Type A" (J. Greenberg) [7], diagnosis of conflict resolution strategies D. Johnson and F. Johnson;

b) the choice of non-constructive ways of behaving in stressful situations - methods "Coping behaviour in stressful situations" (S. Norman, D. Endler, D. James in the adaptation of T. Kriukova, 2002) [7].

c) "Peculiarities of solving production problems in crises: a case study" (author's development);

d) low efficiency of professional duties - Scale 6 "Changes in behaviour and activities" of the methodology "Personal profile of the crisis" (A. Taras, 2003) [7].

The study was conducted among the students of the State Institution of the Higher Education "University of Educational Management" (Central Institute of Postgraduate Education). The total sample size was more than 2000 (2060) heads of educational organizations from different regions of Ukraine, who have undergone advanced training in this institution for the last 5 years. We processed the data and made the presentation of results with the statistical software package SPSS (version 21.0).

\section{RESULTS AND DISCUSSION}

\subsection{Results}

Approbation of the model of the occupational crisis of heads of educational organizations and a set of psychodiagnostic techniques used at studying its manifestations have proved their validity and ability to obtain the results that allow determining specific actions to overcome such a crisis taking into account individual characteristics. Internal reliability of the overall measure was enough high: $\alpha$-Cronbach's coefficient for the indicators individual components of the model was between 0.62 and up to 0.97 . The coefficients correlation Spearmen between components of model were enough: between cognitive and reflective component and affective component was 0.547 and between conative and regulatory and affective component and cognitive and reflective 
component and conative and regulatory component were 0.706 and 0.559 respectively $(\mathrm{p}<0.01)$.

Thus, the results of the study of the cognitive and reflective component of the occupational crises revealed the peculiarities of the ideas of the heads of secondary education institutions about the nature and manifestations of occupational crises. In particular, the analysis of the responses of the heads of secondary education institutions to the essence of the concept of "crisis" shows a low level of understanding for a large number of respondents. It was stated that $35.2 \%$ of respondents have a "mediocre" level of understanding, $32.7 \%$ - "moderate", and the rest "imperfect" $(17.3 \%)$ and "weak" (13.6\%). Only $1.2 \%$ of respondents are characterized by a "perfect" level of understanding of the essence of the concept of "personality crisis", clearly identify the signs of such crises and so on. The heads also find it difficult to identify the types of personality crises. A third (35.2\%) of respondents could not answer this question at all, which may indicate a lack of clear theoretical knowledge about personality crises or the inability to form their answers.

Insufficient level of understanding of the content and ways of constructive overcoming of occupational crises of the individual by the heads of general secondary education institutions was established, namely: low level of such understanding was found in $25.3 \%$, medium - in $54.9 \%$ and high - only in $19.8 \%$ studied.

The respondents have an insufficient level of skills "to reflect, analyze professional activities, adequately assess themselves" (49.2\%), "self-improvement, fight with their weaknesses, to carry out self-regulation" (29.1\%), "to maintain the socio-psychological climate, prevent and resolve conflicts, create a positive" $(27.3 \%)$, "interact, work in a team, choosing an adequate communication style depending on the situation" (21.8\%), "make decisions quickly" (9.1\%).

According to the generalization of the levels of manifestation of all the above indicators, the levels of formation of the occupational crisis in the heads of educational organizations by components were revealed (Table 1)

Table 1 The levels of formation of the occupational crisis in the heads of educational organizations by components

\begin{tabular}{|c|c|c|c|c|c|}
\hline \multirow{2}{*}{ 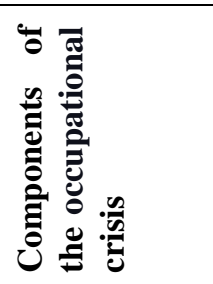 } & \multicolumn{5}{|c|}{$\begin{array}{l}\text { Levels of manifestation, number of } \\
\text { investigated, in } \%\end{array}$} \\
\hline & 3 & 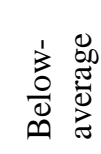 & 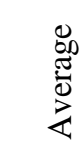 & 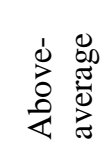 & 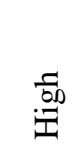 \\
\hline $\begin{array}{l}\text { Cognitive and } \\
\text { reflective }\end{array}$ & 17.3 & 30.7 & 49.3 & 20.7 & 0.0 \\
\hline Affective & 3.2 & 11.4 & 59.4 & 22.5 & 3.5 \\
\hline $\begin{array}{l}\text { Conative and } \\
\text { regulatory }\end{array}$ & 12.9 & 23.5 & 47.0 & 14.1 & 2.5 \\
\hline
\end{tabular}

The data given in table 1 has shown a rather threatening picture for a significant number of surveyed heads. Thus, almost half of the respondents $(48 \%)$ show the low and below-average level of knowledge to overcome occupational crises; only $15 \%$ of heads have belowaverage and low levels of emotional experiences of professional difficulties, which indicates a decrease in their dependence on stress, a probable influx of forces, intensification of activities, special clarity and clarity of thought. Indicators of the conative and regulatory component of the occupational crisis of heads of educational organizations also indicate significant difficulties of a significant number of heads in the constructive regulation of its course. In particular, only $36.6 \%$ of people characterized by a lack of need for constant conscious planning and programming of their behaviour, insecure behaviour in uncertain life and professional situations, developed a low and below-average level of ability to successfully solve complex professional situations.

\subsection{Discussion}

The model of occupational crises of heads of educational institutions is an integral characteristic (system of measures), which indicates the level of manifestation of the professional crisis of psychological spheres of heads (cognitive and reflective, affective, conative and regulatory) and is manifested depending on levels and ways of expressing, and different ways out of the occupational crises that stimulate constructive change.

Monitoring the occupational crisis is important not only to record the degree of its manifestations in heads of education but, above all, to develop a strategy for overcoming it constructively and to implement it in the appropriate model. The use of computer monitoring tools allows quickly covering lots of subjects and obtaining information, performing qualitative analysis, and, if necessary, easily importing data from Google spreadsheets for processing cognitive and reflective, affective and conative and regulatory aspects of heads of educational organizations [12].

The desire to develop a model for overcoming occupational crises for employees of educational institutions, including heads, requires a concerted effort with some dynamics to recognize the professional self-concept, in turn confirming its social value in the eyes of others. But this will become impossible and there will be no motivation to initiate the process if new conditions are not created for the implementation of educational activities. After all, in this relationship of mutual recognition, when an occupational crisis threatens [28]: both teachers and students are prisoners of the problems and constraints that underlie the absurdity of the situation in educational institutions. Building a different connection with knowledge, on the part of students, and a different way of life of the profession, on the part of teachers, must take place simultaneously. Building professionalism for educators does not precede, but rather accompanies the construction 
of new relationships with students, colleagues, management.

The actualization and search for social support of personality resources is a constructive way of crisis management since it facilitates the teacher to retain his/her professional status and stay in the profession [27].

Among such resources, as Critical Situation Management Competency, are, in particular: stress Resistance (sees the situation as interesting, is optimistic about achieving success, open to change, accepts hardships of situation, etc), coping mechanisms (the perception that a solution can be found, accepts solution may not be best but will have to do due to the urgency of the situation, etc), motivation (focused on achieving a goal relevant to the positive outcome of the situation, etc), information processing (matches the complexity of situation assessment with task complexity, etc) [29].

Based on the generalization of results of the levels of the specified indicators of overcoming of occupational crises at heads of the educational organizations are allocated:

- low (primary) - the ability to intuitively identify the problem and the causes that cause some violations in the activities of heads of educational organizations, etc.;

- average (adaptation) - a reassessment of professional plans, relationships with colleagues and all participants in the educational process; search for ways out of the crisis;

- high (transformative) - a clear awareness of the impossibility of acting in the usual way; constructive attitude to the events in the life of the leader, which is associated with active, transformative activities and brings the individual to a higher level of development.

\section{CONCLUSION}

The first experience tested the model of the professional crisis of heads of educational organizations and a set of psychodiagnostic techniques aimed at studying its manifestations, proved their validity and the ability to obtain results that allow determining specific actions to overcome such a crisis based on individual characteristics. The results of the study show that a small number of heads of educational organizations tend to constructively resolve professional crises, constructively deal with professional emergencies, as well as: focuses on knowledge and understanding of the specifics of professional crises; motivates to solve difficulties and obstacles independently; knows and adjusts its value system, which helps the organization to develop and progress towards professional growth; indicates the possession of experience, skills and abilities for a positive emotional response to the challenges of society; builds harmonious relationships in the team through effective personal self-regulation.

Most leaders are unable to find a constructive way out of situations and require special psychological interventions that ensure the development of the ability of heads of educational organizations to constructively resolve the professional crisis, taking into account the individual characteristics of its course; to develop programs of psychological crisis interventions that will help not only to overcome crises but also to create conditions for the development of cognitive and reflective, affective and conative and regulatory aspects of the heads of educational organizations.

\section{REFERENCES}

[1] B. Farber, "Crisis in education: Stress and burnout in American teacher", 1991, San Francisco: Jossey-Bass

[2] T. Feinberg, "Caring for our caregivers", The Education Digest, 67(9), pp.8-11, 2002.

[3] C. Maslach \& M. Leiter, "The truth about burnout. How organizations cause personal stress and what to do about it", 1997, California, San Francisco: Jossey-Bass publishers

[4] K. Sadeghi \& S. Khezrlou, "The experience of burnout among English language teachers in Iran: self and other determinants", Teacher Development, 20(5): pp.631-647, 2016. Doi:

https://doi.org/10.1080/13664530.2016.1185028

[5] H. Soodmand Afshar \& M. Doosti, "Investigating the impact of job satisfaction/dissatisfaction on Iranian English teachers' job performance", Iranian Journal of Language Teaching Research, 4(1), pp.97-115, 2016.

[6] A. Villa \& E. Calvete, "Development of the teacher self-concept evaluation scale and its relation to burnout", Studies in Educational Evaluation, 27, pp.239-255, 2001.

[7] O. Bondarchuk, "Methods of research of features of psychological readiness of heads of the educational organizations to activity in the conditions of changes" p. 148, 2014 Kyiv.

[8] O. Brukhovetskaya, "Psychology of professional tolerance of heads of secondary schools", Monog., p. 360,2018 , Kyiv.

[9] L. Karamushka, M. Moskaljov, "Psychology of preparation of future heads for change management in the organization”, Monog., p. 216, 2011, Kyiv-Lviv.

[10] O. Chorosova, R. Gerasimova, "Questionnaire for identifying crisis-causing factors and factors for overcoming professional crises 2006/9”, Practice of administrative work in school. №4. pp. 55-57.

[11] N. Sadovnikova, T. Sergeeva, M. Suraeva and O. Kuzmina, "Phenomenological Analysis of Professional Identity Crisis Experience by Teachers", International Journal Of Environmental \& Science Education, Vol. 11, No. 14, pp. 6898-6912, 2016. 
[12] O. Bondarchuk, V. Balakhtar and K. Balakhtar, "Monitoring of the Quality of the Psychological Component of Teacher's Activity of the High Education Institutions with the help of Google Drive tools", E3S Web of Conferences Volume 166, 22 April 2020, 100242020 International Conference on Sustainable Futures: Environmental, Technological, Social and Economic Matters, ICSF 2020, Kryvyi Rih, Ukraine;

[13] F. Dombrowski, "Psychological First Aid During COVID-19”, 2020,

https://www.naadac.org/psychological-first-aid-webinar

[14] M. Maps, "From crisis management to recovery", In Psych. Vol 41. Is. 3, 2019

https://www.psychology.org.au/formembers/publications/inpsych/2019/june/From-crisismanagement-to-recovery

http://dlse.multycourse.com.ua/ua/page/15/53\#1

[15] T. Titarenko, "The life world of the person: the structural-genetic approach”, dis, p. 305, 1994, Kyiv.

[16] I. Cherezova, "Psychology of life crises of the personality”, p. 193, 2016, Berdyansk.

[17] K. Eastham, D. Coates \& F. Allodi, "The concept of crisis. Canadian Psychiatric Association Journal", 15, pp.463-472, 1970.

[18] H. Freudenberger, "Staff burnout. Journal of Social Issues”, 30(1), 159-165, 1974, p. 160.

[19] T. Holmes and R. Rahe, "The social readjustment rating scale", Journal of Psychosomatic Research, vol. 11, Aug., 1967, pp. 213-218

[20] R. Rahe and T. Holmes, "Predicting illness-'Life Crisis"”. Psychological Spectator, vol. 3, No. 12, 1966 (5)
[21] C. Murray Parkes "Effects of bereavement on physical and mental health - a study of the medical records of widows", British Journal of Medical Psychiatry, vol. 38, March, pp. 1-12, and 13-26.

[22] I. Malkina-Pykh, "Psychological help in crisis situations", p. 928, 2008, M .: Exmo.

[23] N. Golikov, "Socio-psychological support of the teacher: conditions, methods, technologies of implementation”, Bull. of Tyumen State Univer., № 2. pp. 210-219, 2004.

[24] M. Hutri \& M. Lindeman, "The role of stress and negative emotions in an occupational crisis". Journal of Career Development, 29(1), pp.19-36, 2002.https://doi.org/10.1023/A:1016547718122

[25]A. Moskalyova, "Training of heads of educational organizations to prevent professional crises of the individual", a special course, p. 28, 2010, Kyiv.

[26] E. Donchenko, T. Titarenko, "Personality: conflict, harmony", p. 175, 1989,.Kyiv.

[27] L. Karamushka, "Technologies of organizational psychologists”, p .366, 2005, Kyiv.

[28] R. Canario, “A escola: das "promessas” às “incertezas”, Educaçã o Unisinos, 12 (2), pp. 73-81, 2008. Retrieved from:

http://www.unisinos.br/revistas/index.php/educacao

[29] G. Buck, "The role of psychological factors in the management of crisis situations", University of Westminster, 2003,

https://www.continuitycentral.com/crisispaper.pd 